\title{
Avaliação da qualidade de materiais educativos em saúde bucal
}

\author{
Filipe Massaruto (EM), Kelly Cauane Ramalho da Cunha (EM), Thais Melo Farias (EM), Miguel Morano \\ Júnior (PQ), Fábio Luiz Mialhe (PQ).
}

\section{Resumo}

O objetivo deste estudo foi avaliar o nível de compreensão de alunos do ensino médio sobre as informações presentes em uma amostra de fôlderes em saúde bucal produzidos por empresas do ramo odontológico. Os folders tratavam dos seguintes temas: hipersensibilidade dentinária, câncer bucal, cárie dentária, saúde bucal direitos de todos e doenças periodontais. A maioria dos alunos respondeu que achou os materiais bem elaborados, que os folderes apresentavam informações suficientes, que o tamanho das letras era adequado, que as recomendações disponibilizadas nos materiais eram fáceis de serem seguidas e úteis, e que aprenderam coisas novas a partir da leitura dos fôlderes. Conclui-se que a maioria dos alunos apresentou um bom entendimento das informações disponibilizadas nos impressos educativos em saúde bucal e que os materiais trouxeram informações novas e fáceis de serem implementadas na vida diária.

Palavras Chave: educação em saúde bucal, informação, comunicação em saúde

\section{Introdução}

Embora os materiais educativos impressos seja amplamente utilizados nos processos educativos em saúde, estudos verificam que estes nem sempre são elaborados de forma adequada, principalmente no que se refere ao nível de legibilidade do material, a presença jargões profissionais e palavras difíceis, e mesmo o próprio layout do material, tornando-o desinteressante à população-alvo a que se destina (Gal e Prigat, 2005). Caso os indivíduos não consigam compreender as informações disponibilizadas nos materiais impressos, sua função educativa será limitada. Enquanto as áreas de medicina, farmácia e enfermagem vêm estudando já há algum tempo as dificuldades de legibilidade e compreensão dos materiais impressos, a área odontológica apresenta ainda poucos estudos nesta linha de pesquisa (Hendrickson et al., 2006). Desta forma, o objetivo do presente estudo foi avaliar o nível de compreensão de alunos do ensino médio sobre as informações presentes em uma amostra de cinco fôlderes em saúde bucal produzidos por empresas do ramo odontológico.

\section{Resultados e Discussão}

A amostra do estudo foi composta por cerca de 200 alunos do ensino médio. A cada semana, os pesquisadores disponibilizavam para os alunos, em sala de aula, um folder educativo e um questionário contendo critérios de avaliação sobre a qualidade do mesmo (Harvey e Fleming, 2003) previamente testado. Os folders tratavam sobre os seguintes temas: hipersensibilidade dentinária; câncer bucal; cárie dentária; saúde bucal, direitos de todos e doenças periodontais.
De uma forma geral, a maioria dos alunos respondeu que: achou os materiais bem elaborados; cada folder apresentava quantidade de informações suficiente; o tamanho das letras dos folders era adequado; as recomendações nos materiais eram fáceis de serem seguidas; os materiais foram considerados muito úteis e que aprenderam coisas novas a partir da leitura dos fôlderes.

Os temas doenças periodontais e hipersensibilidade dentinária foram aqueles que apresentaram maior dificuldade de compreensão de algumas palavras.

\section{Conclusões}

Concluiu-se que a maioria dos alunos do ensino médio participantes do presente estudo apresentou um bom entendimento das informações disponibilizadas nos impressos educativos em saúde bucal e que os materiais trouxeram informações novas e fáceis de serem implementadas na vida diária.

\section{Agradecimentos}

Agradecemos à Pró-Reitoria de Pesquisa da Unicamp e ao Conselho Nacional de Desenvolvimento Científico e Tecnológico pelo apoio disponibilizado.

${ }^{1}$ Gal I, Prigat A. Why organizations continue to create patint information leaftles with readability and usability problems: an exploratory study. Health Educ Res. 2005; 20:485-93.

${ }^{2}$ Hendrickson RL, Huebner CE, Riedy CA. Readability of pediatric health materials for preventive dental care. BMC Oral Health 2006; 6:1-9.

${ }^{3}$ Harvey HD, Fleming P. The readability and audience acceptance of printed health promotion materials used by environmental health departments. J Environ Health. 2003;65:22-8. 